\title{
Expression of circadian genes correlates with liver metastasis and outcomes in colorectal cancer
}

\author{
TAKASHI OSHIMA ${ }^{1}$, SEIICH TAKENOSHITA ${ }^{2}$, MAKOTO AKAIKE $^{3}$, CHIKARA KUNISAKI $^{1}$, SHOICH FUJII $^{1}$, \\ AKITO NOZAKI ${ }^{1}$, KAZUSHI NUMATA $^{1}$, MANABU SHIOZAWA $^{3}$, YASUSHI RINO ${ }^{4}$, \\ KATSUAKI TANAKA $^{1}$, MUNETAKA MASUDA ${ }^{4}$ and TOSHIO IMADA ${ }^{4}$ \\ ${ }^{1}$ Gastroenterological Center, Yokohama City University Medical Center 4-57 Urafune-cho, Minami-ku, \\ Yokohama, Kanagawa 232-0024; ${ }^{2}$ Department of Surgery, Fukushima Medical University, 1 Hikarigaoka, \\ Fukushima 960-1247; ${ }^{3}$ Department of Surgery, Kanagawa Cancer Center, 1-1-2 Nakao, Asahi-ku, Yokohama, \\ Kanagawa $241-0815 ;{ }^{4}$ Department of Surgery, Yokohama City University, \\ 3-9 Fukuura, Kanazawa-ku, Yokohama, Kanagawa 236-0004, Japan
}

Received December 14, 2010; Accepted February 7, 2011

DOI: 10.3892/or.2011.1207

\begin{abstract}
Circadian rhythms are daily oscillations in various biological processes, generated by the feedback loops of eight core circadian genes: Period1 (Per1), Period2 (Per2), Period3 (Per3), Cryptochrome1 (Cry1), Cryptochrome2 (Cry2), Clock, Bmall and Casein Kinase I $\varepsilon(C K I \varepsilon)$. Recent studies have suggested that circadian genes participate in the growth and development of various cancers. This study examined the relations of circadian gene expression to clinicopathological factors and outcomes in patients with colorectal cancer. We studied surgical specimens of cancer tissue and adjacent normal mucosa obtained from 202 patients with untreated colorectal cancer. The relative expression levels of the circadian genes in the specimens were measured by quantitative real-time, reverse-transcription polymerase chain reaction. Expression of the Clock gene and the CKIE gene in cancer tissue were significantly higher compared to that in adjacent normal mucosa. Expression of the Perl and Per3 genes in cancer tissue was significantly lower compared to that in adjacent normal mucosa. Analysis of the relations between clinicopathological features and expression of the eight circadian genes in cancer tissue showed that high expression of the Bmall gene and low expression of the Perl gene correlated with liver metastasis. On analysis of the relations between outcomes and gene expression, high expression of the Per2 gene was associated with significantly better outcomes than low expression of the Per 2 gene. Overexpression of the Bmall gene and reduced expression of
\end{abstract}

Correspondence to: Dr Takashi Oshima, Gastroenterological Center, Yokohama City University, 4-57 Urafune-cho, Minami-ku, Yokohama, Kanagawa 232-0024, Japan

E-mail: ohshimatakashi@yahoo.co.jp

Key words: circadian genes, colorectal cancer, liver metastasis, prognostic factor, Bmal1, period1, period 2 the Perl gene may thus be useful predictors of liver metastasis. Moreover, reduced expression of the Per 2 gene may be a predictor of outcomes in patients with colorectal cancer.

\section{Introduction}

Circadian rhythms are daily oscillations in various biologic processes. In mammals, the master circadian pacemaker is located in the suprachiasmatic nuclei (SCN) (1). The master circadian clock coordinates peripheral circadian clocks within virtually every cell in the body (2). This coordination is accomplished directly through autonomic nervous system innervation and indirectly through daily rhythmic synthesis and release of an array of hypothalamic, pituitary, and dispersed endocrine hormones (3-6).

The molecular mechanism of circadian oscillation in the SCN and peripheral cells is based on the feedback loops of eight core circadian genes $(3,7,8)$. These eight genes are Periodl (Per1), Period2 (Per2), Period3 (Per3), Cryptochrome1 (Cry1), Cryptochrome2 (Cry2), Clock, Bmall, and Casein Kinase I 8 $(C K I \varepsilon)$. The feedback loops of the eight core circadian genes are as follows. The Clock gene remains steady throughout the 24-h day. High levels of Bmal1 promote the formation of Bmal1/Clock heterodimers. These heterodimers bind to E-box sequences in the promoters of the Cry and Per genes to activate transcription. Bmal1/Clock heterodimers can also inhibit Bmall transcription. After transcription and translation, the Per proteins accumulate in the cytoplasm and are phosphorylated by CKI $\varepsilon$. The phosphorylated forms of Per are unstable and are degraded by ubiquitylation. Cry accumulates in the cytoplasm, promoting the formation of stable Per/Cry/CK1ع complexes, which enter the nucleus. Once in the nucleus, Cry disrupts the Bmal1/Clock-associated transcriptional complex, resulting in the inhibition of Cry and Per transcription and the derepression of Bmal1 transcription (Fig. 1). In the peripheral tissues, the molecular clock coordinates the transcription of the circadian genes. The circadian genes are largely tissue specific and link key tissue functions to the circadian environ- 


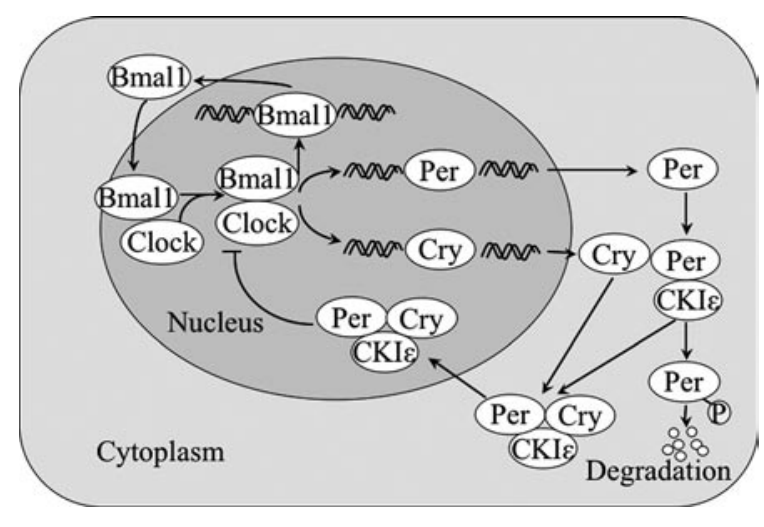

Figure 1. The feedback loops of eight core circadian genes. The molecular mechanism of circadian oscillation in the SCN and peripheral cells is based on the feedback loops of eight core circadian genes. The Clock gene remains steady throughout the 24-h day. High levels of Bmall promote the formation of Bmal1/Clock heterodimers. These heterodimers bind to E-box sequences in the promoters of the Cry and Per genes to activate transcription. Bmal1/ Clock heterodimers can also inhibit Bmall transcription. After transcription and translation, the Per proteins accumulate in the cytoplasm and are phosphorylated by CKI $\varepsilon$. The phosphorylated forms of Per are unstable and are degraded by ubiquitylation. Cry accumulates in the cytoplasm, promoting the formation of stable Per/Cry/CK1e complexes, which enter the nucleus. Once in the nucleus, Cry disrupts the Bmal1/Clock-associated transcriptional complex, resulting in the inhibition of Cry and Per transcription and the derepression of Bmall transcription.

ment, making these key functions available at specific times during each day, when they are most needed (9-11).

Disruption of circadian organization has significant effects on human health, causing sleep disorders, gastrointestinal and cardiovascular illnesses, and depression. It is also associated with an increased incidence of several epithelial cancers (12-15). In mouse models, transplanted tumors grow twice as fast in SCN-lesioned mice than in sham-lesioned animals (16). These studies have suggested a close connection between circadian organization and the development of various cancers. Relations between circadian genes and cancer have been demonstrated in recent years. The host circadian clock has been reported to play an important role in the endogenous control of tumor progression (16). As for circadian genes, Bmall was shown to be a positive regulator of tumor growth and metastasis in cancer (17). Moreover, overexpression of Perl in prostate cancer cells causes significant growth inhibition and apoptosis (18). In addition, Per2 plays a key role in tumor suppression, controlled by genes such as $c$-myc and cyclin $D l$ through the activity of Bmall/Clock heterodimers (19), and Per2 gene overexpression induces cancer cell apoptosis (20). Per2 overexpression has also been found to inhibit the growth of pancreatic cancer cells and to act synergistically with cisplatin (21). However, studies assessing the relations of circadian gene expression to clinicopathological features and outcomes in colorectal cancer have not been reported. We therefore examined whether the expressions of circadian genes were related to clinicopathological characteristics and outcomes in patients with colorectal cancer.

\section{Materials and methods}

Patients and samples. We studied surgical specimens of cancer tissue and adjacent normal mucosa obtained from
202 patients with untreated colorectal cancer. The patients underwent surgery at Yokohama City Medical Center, Gastroenterological Center, and at Kanagawa Cancer Center from January 2002 through January 2005. The duration of observation was longer than 5 years. Informed consent was obtained from each patient, and the ethics committees of Yokohama City Medical Center and Kanagawa Cancer Center approved the protocol before initiation of the study.

All tissue samples were embedded in O.C.T. compound (Sakura Finetechnical Co., Ltd., Tokyo, Japan) and immediately stored at $-80^{\circ} \mathrm{C}$ until use. No patient had any other malignancies. The histopathological features of specimens stained with hematoxylin and eosin were examined, and sections that consisted of $>80 \%$ cancer cells were used to prepare total RNA.

Quantitative real-time, reverse-transcription polymerase chain reaction $(P C R)$. Total RNA isolated from colorectal cancer and adjacent normal mucosa was prepared with the use of TRIzol (Gibco, Life Tech, Gaithersburg, MD, USA). Complementary DNA (cDNA) was synthesized from $2 \mu \mathrm{g}$ of total RNA with an iScript cDNA Synthesis Kit (Bio-Rad Laboratories, Hercules, CA, USA). After synthesis, the cDNA was diluted 1:4 with water and stored at $-20^{\circ} \mathrm{C}$ until use. Quantitative real-time PCR was performed with an iQ SYBRGreen Supermix (Bio-Rad Laboratories). PCR reactions were carried out in a total volume of $15 \mu \mathrm{l}$ containing cDNA derived from $75 \mathrm{ng}$ of mRNA, $0.27 \mu \mathrm{M}$ of each primer, $7.5 \mu \mathrm{l}$ of iQ SYBR-Green Supermix containing dATP, dCTP, dGTP, and dTTP at concentrations of $400 \mu \mathrm{M}$ each, and 50 units $/ \mathrm{ml}$ of iTag DNA polymerase. The PCR consisted of $10 \mathrm{~min}$ at $94^{\circ} \mathrm{C}$, followed by 50 cycles of denaturation of the cDNA for $30 \mathrm{sec}$ at $94^{\circ} \mathrm{C}$, annealing for $30 \mathrm{sec}$ at an appropriate temperature (Table I), and a primer extension for $1 \mathrm{~min}$ at $72^{\circ} \mathrm{C}$ followed by $10 \mathrm{~min}$ at $72^{\circ} \mathrm{C}$. The PCR primer sequences of Perl, Per 2 , Per3, Cryl, Cry2, Clock, Bmall, CK1E, and $\beta$-actin, used as an internal control, are shown in Table I.

Statistical analysis. Gene expression levels of colorectal cancer were compared with those of adjacent normal mucosa by the Wilcoxon test. Relations between gene expression and potential explanatory variables, including age, gender, tumor size, histological type, depth of invasion, lymph node metastasis, location, lymphatic invasion, venous invasion, and liver metastasis, were evaluated with the $\chi^{2}$ test. The postoperative survival rate was analyzed by the Kaplan-Meier method, and differences in survival rates were assessed with the log-rank test. A Cox proportional hazard regression model was used for multivariate analyses. All statistical analyses were performed using IBM SPSS Statistics 18.0 (SPSS, Inc., Chicago, IL, USA). Two-sided P-values were calculated, and a difference was considered significant if the P-value was $<0.05$.

\section{Results}

Comparison of circadian gene mRNA expression between colorectal cancer tissue and adjacent normal mucosa. Clock and $C K 1 \varepsilon$ gene expression levels were higher in cancer than in adjacent normal mucosa $(\mathrm{P}<0.0001, \mathrm{P}<0.0001$; Fig. $2 \mathrm{~F}$ and $\mathrm{H})$. Perl and Per3 gene expression levels were higher in adjacent 
Table I. PCR primers and conditions.

\begin{tabular}{|c|c|c|c|}
\hline Gene & Primer & Temperature $\left({ }^{\circ} \mathrm{C}\right)$ & Product size (bp) \\
\hline Perl & $\begin{array}{l}\text { 5'-AGGCAACGGCAAGGACTC-3' } \\
\text { 5'-GGCTGTAGGCAATGGAACTG-3' }\end{array}$ & 60.2 & 101 \\
\hline Per2 & $\begin{array}{l}\text { 5'-CTACAGCAGCACCATCGTC-3' } \\
\text { 5'-CCACTCGCAGCATCTTCC-3' }\end{array}$ & 58.9 & 78 \\
\hline Per3 & $\begin{array}{l}\text { 5'-TGGTGGTGGTGAATGTAAGAC-3' } \\
\text { 5'-GGCTGTGCTCATCGTTCC-3' }\end{array}$ & 57.2 & 104 \\
\hline Cryl & $\begin{array}{l}\text { 5'-CAACCTCCATTCATCTTTCC-3' } \\
\text { 5'-CTCATAGCCGACACCTTC-3' }\end{array}$ & 58.9 & 151 \\
\hline Cry2 & $\begin{array}{l}\text { 5'-TGGGCTTCTGGGACTGAG-3' } \\
\text { 5'-GGTAGGTGTGCTGTCTTAGG-3' }\end{array}$ & 57.2 & 136 \\
\hline Clock & $\begin{array}{l}\text { 5'-GCAGCAGCAGCAGCAGAG-3' } \\
\text { 5'-CAGCAGAGAGAATGAGTTGAGTTG-3' }\end{array}$ & 61.9 & 149 \\
\hline Bmall & $\begin{array}{l}\text { 5'-TGCCACCAATCCATACACAGAAG-3' } \\
\text { 5'-TTCCCTCGGTCACATCCTACG-3' }\end{array}$ & 60.9 & 123 \\
\hline CKIE & $\begin{array}{l}\text { 5'-TCAGCGAGAAGAAGATGTC-3' } \\
\text { 5'-GAAGAGGTTGCGGAAGAG-3' }\end{array}$ & 58.9 & 149 \\
\hline$\beta$-actin & $\begin{array}{l}\text { 5'-AGTTGCGTTACACCCTTTCTTGAC-3' } \\
\text { 5'-GCTCGCTCCAACCGACTGC-3' }\end{array}$ & 60.0 & 171 \\
\hline
\end{tabular}
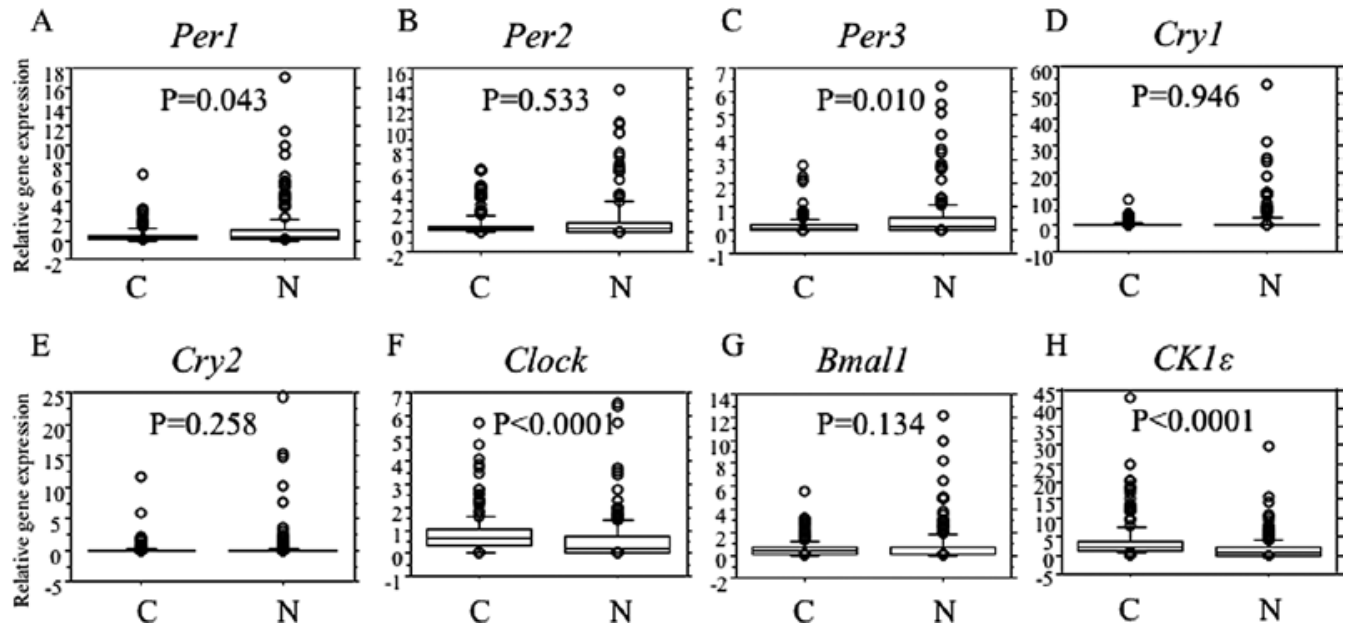

Figure 2. Comparison of circadian gene mRNA expression levels between colorectal cancer tissue (C) and adjacent normal mucosa (N). Box boundaries, the 25 th and 75 th percentiles of the observed values; capped bars, the 10th and 90th percentiles; solid line, median. P-values were calculated by the Wilcoxon test. Clock and CK1E gene expression levels were higher in cancer than in adjacent normal mucosa $(\mathrm{P}<0.001)$. Perl and Per3 gene expression levels were higher in adjacent normal mucosa than in cancer. Per2, Cry1, Cry2, and Bmall gene expression levels were similar in cancer and adjacent normal mucosa.

normal mucosa than in cancer $(\mathrm{P}=0.043, \mathrm{P}=0.010$; Fig. $2 \mathrm{~A}$ and C). Per2, Cryl, Cry2, and Bmall gene expression levels were similar in cancer and adjacent normal mucosa (Fig. 2B-G).

Relations of circadian gene expression levels to clinicopathological features. Expression levels of the circadian genes were categorized as low or high according to their median values. The relations between the expression levels of these genes and clinicopathological features were then examined. Expression levels of the circadian genes were unrelated to age, gender, tumor size, lymph node metastasis, lymphatic invasion, and venous invasion. High expression of the Bmall gene and low expression of the Perl gene correlated with liver metastasis (Table II).

Relations of Bmall and Perl gene expression levels to liver metastasis. The highest rate of liver metastasis was associated with high expression of the Bmall gene and low expression of the Perl gene (Fig. 3). 


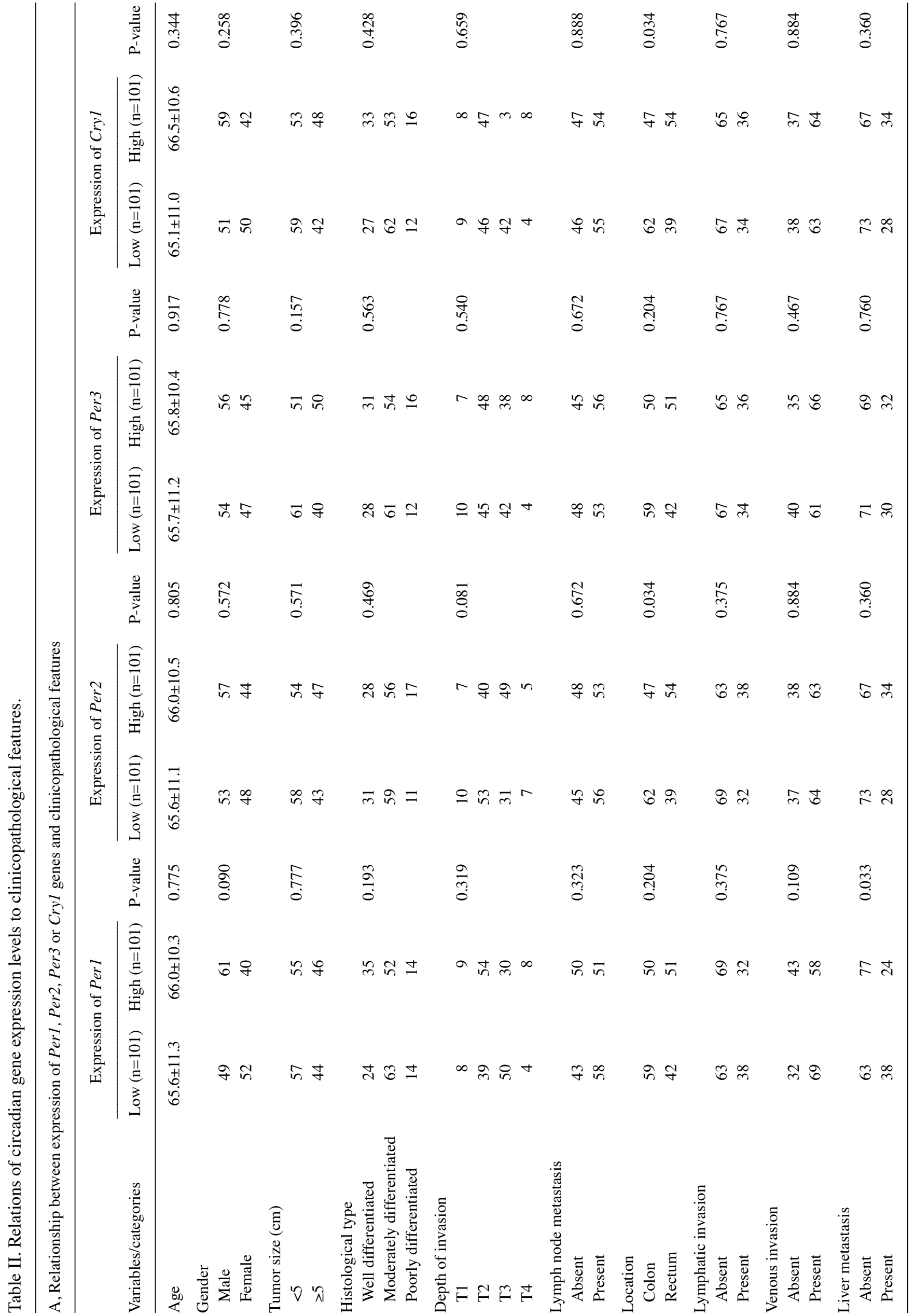




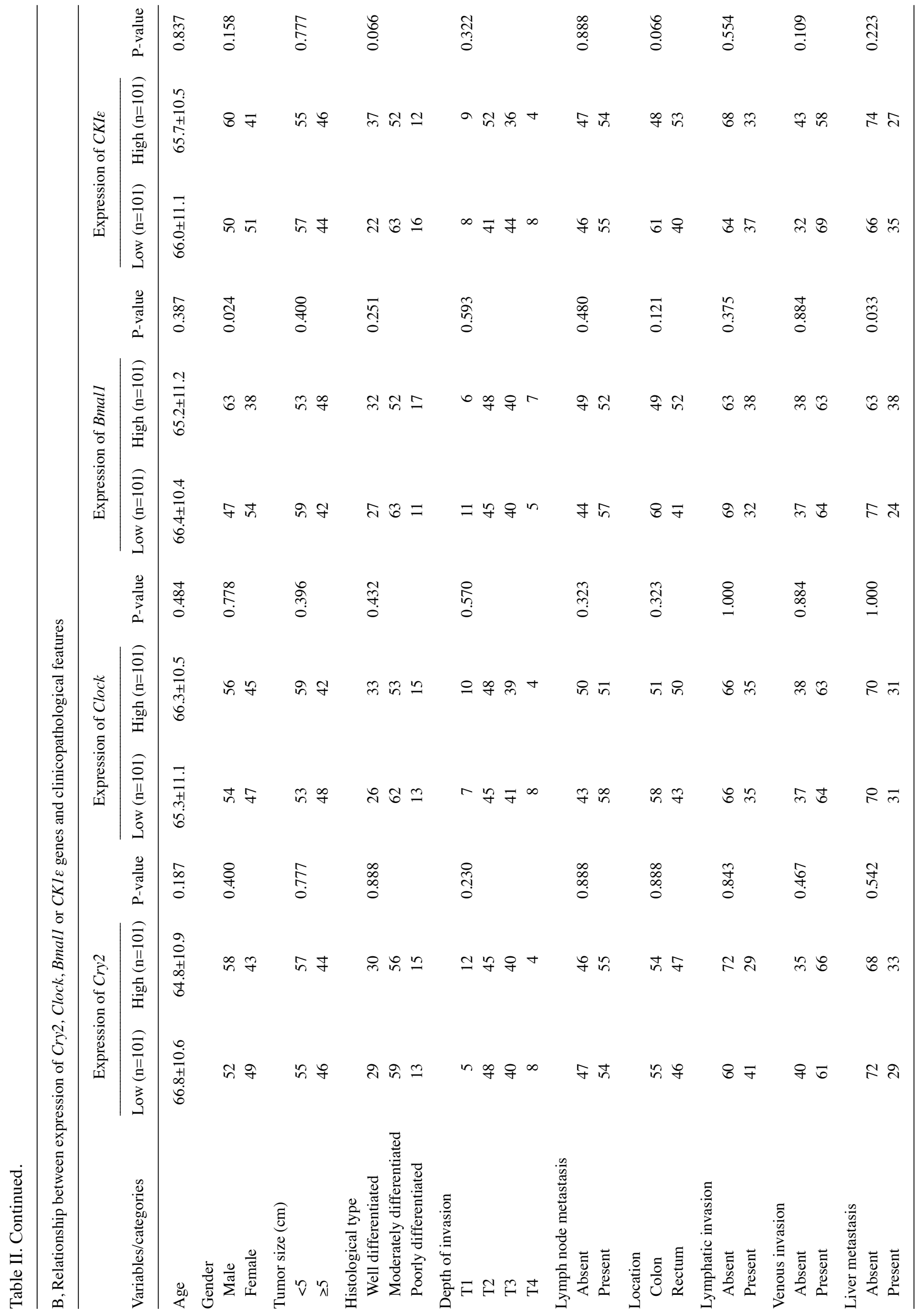


Table III. Univariate analysis of clinicopathological factors and circadian genes expression for outcomes.

Survival rate $(\%)$

Variables/categories no. 1-year 3-year 5-year P-value

\begin{tabular}{lrrrrr}
\hline Age (years) & & & & & \\
$<65$ & 92 & 95.6 & 87.9 & 75.3 & 0.3202 \\
$\geq 65$ & 110 & 90.9 & 77.3 & 71.7 &
\end{tabular}

Gender

Male

Female

$92 \quad 93.5$

79.9

71

0.4833

Tumor size $(\mathrm{cm})$

$<5$

$112 \quad 96.4$

$83.7 \quad 75.1$

$\geq 5$

9087.8

92.2

$81.7<0.0001$

Histological type

Wel, mod

Por

$\begin{array}{rrrr}174 & 95.4 & 85.4 & 75.1 \\ 28 & 74.3 & 62.4 & 43.3\end{array}$

0.0093

Serosal invasion

$\begin{array}{lrcccc}\text { Absent } & 110 & 96.3 & 92.7 & 91.3 & <0.0001 \\ \text { Present } & 92 & 87 & 69.2 & 57.3 & \end{array}$

Lymph node metastasis

metastasis

$\begin{array}{lrrrrr}\text { Absent } & 93 & 97.8 & 94.6 & 90.5 & <0.0001 \\ \text { Present } & 109 & 87.1 & 70.7 & 58.2 & \end{array}$

Location

Colon

Rectum

$\begin{array}{rrrrr}109 & 92.6 & 86.1 & 77.8 & 0.0941 \\ 93 & 92.5 & 77.9 & 67.0 & \end{array}$

Lymphatic invasion

$\begin{array}{lrllll}\text { Absent } & 132 & 98.5 & 89.9 & 82.3 & <0.0001 \\ \text { Present } & 70 & 81 & 66.8 & 53.2 & \end{array}$

Venous invasion

Absent

Present

$\begin{array}{rlrrr}75 & 96 & 89.2 & 72.6 & 0.1884 \\ 127 & 89.7 & 77.4 & 70.8 & \end{array}$

Liver metastasis

$\begin{array}{lrrrrr}\text { Absent } & 140 & 97.9 & 93.9 & 89.2 & <0.0001 \\ \text { Present } & 62 & 80.4 & 53.8 & 34.2 & \end{array}$

Expression of Perl

High

Expression of Per2

High

10190.1

82

74.6

0.7583

10195

81.2

66.7

Low

$\begin{array}{lllll}101 & 95 & 91 & 81.2 & 0.0048\end{array}$

$\begin{array}{llll}101 & 90.1 & 72.5 & 63.3\end{array}$

Expression of Per3

$\begin{array}{llllll}\text { High } & 101 & 94.2 & 87.9 & 79.8 & 0.0551 \\ \text { Low } & 101 & 91.3 & 76.5 & 64.2 & \end{array}$

Expression of Cryl

High

$\begin{array}{llll}101 & 94.1 & 86.2 & 79.9\end{array}$

0.0586

Low

$\begin{array}{llll}101 & 91 & 73.3 & 66.3\end{array}$

Expression of Cry2

High

10190

76.6

69.5

0.0962
Table III. Continued.

\begin{tabular}{llllll}
\hline & \multicolumn{5}{c}{ Survival rate (\%) } \\
\cline { 3 - 5 } & & & & \\
\cline { 3 - 5 } Variables/categories & no. & 1-year & 3-year & 5-year & P-value \\
\hline Expression of Clock & & & & & \\
$\quad$ High & 101 & 92.1 & 83.8 & 69.8 & 0.9903 \\
$\quad$ Low & 101 & 93 & 79.6 & 75.7 & \\
Expression of Bmall & & & & & \\
$\quad$ High & 101 & 90 & 75.9 & 70.7 & 0.1673 \\
$\quad$ Low & 101 & 95 & 87.1 & 74.9 & \\
Expression of CK1E & & & & & \\
$\quad$ High & 101 & 92.1 & 80.6 & 73.4 & 0.7486 \\
$\quad$ Low & 101 & 93 & 82.7 & 70.8 & \\
\hline
\end{tabular}

Survival time was determined using the Kaplan-Meier method and compared using the log-rank test. Wel, well differentiated adenocarcinoma; mod, moderately differentiated adenocarcinoma; por, poorly differentiated adenocarcinoma.

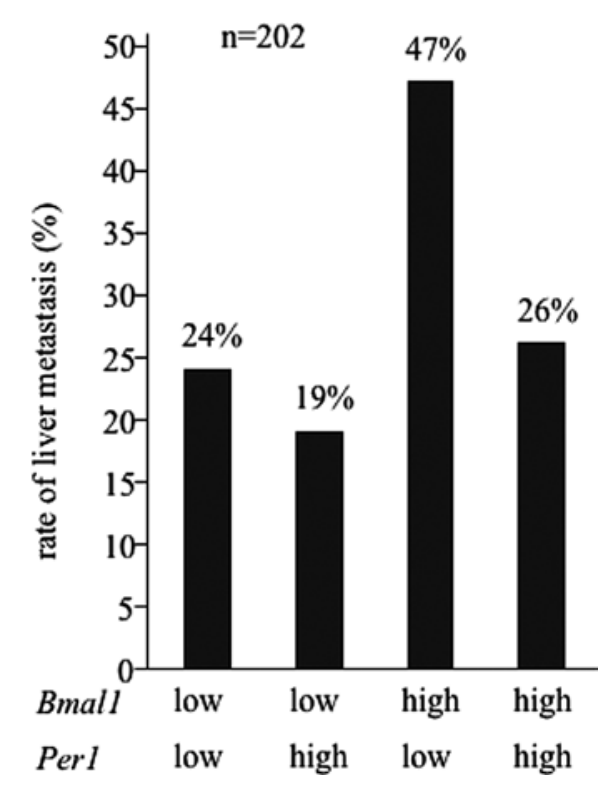

Figure 3. Relations of Bmal1 and Per1 gene expression levels to liver metastasis. The highest rate of liver metastasis was associated with high expression of the Bmall gene and low expression of the Perl gene.

Univariate analysis of clinicopathological factors and the expression levels of the circadian genes for outcomes. Univariate analysis revealed that tumor size, serosal invasion, lymph node metastasis, lymphatic invasion, liver metastasis, and the expression of the Per2 gene positively influenced outcomes (Table III).

Multivariate analysis of clinicopathological factors and the expression levels of the circadian genes for outcomes. On multivariate analysis using Cox proportional hazard regression analysis, the expression of Per 2 gene expression was an independent variable affected outcomes of patients with colorectal cancer $(\mathrm{P}=0.006)$ (Table IV). 
Table IV. Multivariate analysis using Cox proportional hazard regression model.

\begin{tabular}{lccc}
\hline Valiables/categories & Hazard ratio & $95 \%$ CI & P-value \\
\hline $\begin{array}{l}\text { Per2 expression } \\
\text { High vs. low }\end{array}$ & 0.401 & $0.208-0.771$ & 0.006 \\
$\begin{array}{l}\text { Tumor size } \\
<5 \mathrm{~cm} \text { vs. } \geq 5 \mathrm{~cm}\end{array}$ & 0.568 & $0.289-1.118$ & 0.101 \\
$\begin{array}{l}\text { Histological type } \\
\quad \text { Wel, mod vs. por }\end{array}$ & 0.806 & $0.388-1.676$ & 0.564 \\
$\begin{array}{c}\text { Serosal invasion } \\
\text { Present vs. absent }\end{array}$ & 1.378 & $0.616-3.081$ & 0.435 \\
$\begin{array}{c}\text { Lymph node metastasis } \\
\text { Present vs. absent }\end{array}$ & 3.069 & $1.281-7.351$ & 0.012 \\
$\begin{array}{c}\text { Lymphatic invasion } \\
\quad \text { Present vs. absent }\end{array}$ & 1.357 & $0.684-2.689$ & 0.382 \\
$\begin{array}{c}\text { Liver metastasis } \\
\text { Present vs. absent }\end{array}$ & 6.169 & $2.880-13.213$ & $<0.001$ \\
\hline
\end{tabular}

CI, confidence interval; wel, well differentiated adenocarcinoma; mod, moderately differentiated adenocarcinoma; por, poorly differentiated adenocarcinoma.

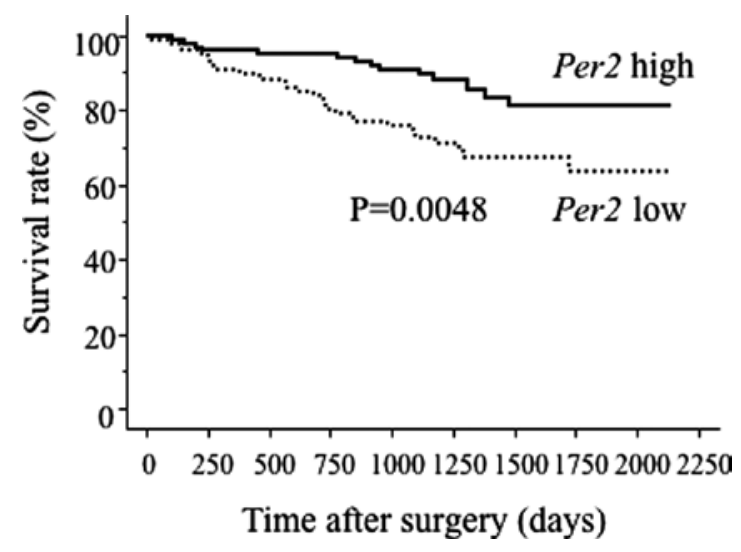

Figure 4. The relations between expressions of the circadian genes and outcomes. High expression of the Per2 gene was associated with significantly better outcomes than low expression of the Per 2 gene $(\mathrm{P}=0.0048)$.

Relations between expressions of the circadian genes and outcomes. High expression of the Per2 gene was associated with significantly better outcomes than low expression of the Per2 gene ( $\mathrm{P}=0.0048)$ (Fig. 4).

\section{Discussion}

In this study, we examined the expression levels of circadian genes in colorectal cancer and in adjacent normal mucosa. We also studied the relations of the expression levels of these genes to outcomes and clinicopathological features. Our results suggest that overexpression of the Bmall gene and reduced expression of the Perl gene are useful predictors of liver metastasis, whereas reduced expression of the Per2 gene is linked to poor outcomes in patients with colorectal cancer.

Several previous studies have compared expression levels of circadian regulators between cancer tissue and adjacent normal mucosa. One study found that $95 \%$ of breast cancer tissue samples displayed loss or deregulated levels of Perl and Per3 proteins as compared with adjacent normal tissue (22). Moreover, the expressions of Per1 and Per2 in both sporadic and familial primary tumors are significantly lower than those in normal breast tissues (23). In human endometrial carcinoma, loss of Per1 protein is commonly observed in tumor cells, but not in the adjacent normal cells (24). A metaanalysis of microarray expression studies showed that Perl is down-regulated in human prostate cancer as compared with normal prostate tissue (18). CK1 $\varepsilon$ gene expression was found to be overexpressed in six kinds of cancer tissues as compared with adjacent normal tissues (25). In our study, Perl and Per3 gene expression levels were lower in cancer than in adjacent normal mucosa. In contrast, $C K 1 \varepsilon$ and Clock gene expression levels were higher in cancer than in adjacent normal mucosa. These results seem to be reasonable for the following reasons. Overexpression of CKIE induces the phosphorylation and degradation of the Period. Reduced Period expression in turn decreases the formation of Per/Cry/CK1ع complexes. Because Per/Cry/CK1ع complexes inhibit the activity of Bmal1/Clock heterodimers, reduced levels of the former promote the activity of the latter. Overexpression of Clock also increases Bmal1/Clock heterodimers, which induce cyclin Dl expression (19). Cyclin D1 promotes the proliferation of cancer cells (26).

We then examined the relations of the expression levels of circadian genes to clinicopathological features. High expression of the Bmall gene and low expression of the Perl gene correlated with liver metastasis. We next examined the relations of Bmall and Perl gene expression levels to liver metastasis. Several previous studies have examined Bmall and Perl. Bmall was suggested to be a positive regulator of tumor growth and metastasis, acting by expressing vascular endothelial growth factor in cancer (27). Bmal1 epigenetic inactivation contributes to the development of hematologic malignancies by disrupting the cellular circadian clock (28). Perl inactivation is thought to play an important role in carcinogenesis (29). Moreover, overexpression of Perl in cancer cells leads to significant growth inhibition and apoptosis (24). In our study, high expression of the Bmall gene and low expression of the Perl gene correlated with liver metastasis. Overexpression of the Bmall gene and reduced expression of the Perl gene might thus promote liver metastasis through the following mechanism. Reduced Perl expression decreases the formation of Per/Cry/CKI $\varepsilon$ complexes. Reduced levels of these complexes promote the activity of Bmal1/Clock heterodimers. Overexpression of Bmal1 also increases the activity of Bmal1/ Clock heterodimers, which induce cyclin D1 expression (19). High levels of cyclin D1 expression increase cancer cell proliferation (26), thereby, promoting liver metastasis.

Finally, we examined the relations between the expressions of circadian genes and outcomes. In the expressions of circadian genes, only the expression of the Per2 gene positively influenced outcomes of patients with colorectal cancer in the univariate analysis. Moreover, the expression of 
the Per2 gene was an independent variable affecting outcomes on multivariate analysis using Cox proportional hazard regression analysis. Previous studies examining the relation between Per2 and cancer have reported that mice without functional Per2 are prone to develop cancer and display altered expression of genes involved in cell cycle regulation, tumor suppression, and apoptosis regulation, such as cyclin D1, cyclin $A, p 53$, $c-M y c, M d m 2$, and $B c l-2$. In particular, $c-M y c$ is controlled by Per2 through the activity of Bmal1/Clock heterodimers (19). Overexpression of the Per 2 gene induces cancer cell apoptosis (20), and inhibits the neoplastic growth of cancer cells (30). Moreover, Per2 gene mutations have been identified in human colorectal and breast cancers (31), and overexpression of Per2 inhibits tumor proliferation in culture as well as in animals $(32,33)$. In our study, high expression of the Per2 gene was associated with significantly better outcomes than low expression of the Per 2 gene. Reduced expression of the Per 2 gene might thus shorten survival in patients with colorectal cancer. The following mechanism is thought to be involved. Reduced expression of the Per2 gene decreases the activity of Bmal1/Clock heterodimers, leading to the induction of $c-M y c$. High levels of c-Myc promote cancer cell proliferation, and reduced expression of Per 2 decreases p53 and increases $\mathrm{Bcl}-2$. Reduced p53 expression and increased $\mathrm{Bcl}-2$ expression repress apoptosis and promote cancer cell survival. Increased cancer cell proliferation and survival lead to poor outcomes.

In conclusion, our results suggest that overexpression of the Bmall gene and reduced expression of the Perl gene are useful predictors of liver metastasis. Moreover, reduced expression of the Per2 gene may be a predictor of outcomes in patients with colorectal cancer.

\section{References}

1. Stephan FK and Zucker I: Circadian rhythms in drinking behavior and locomotor activity of rats are eliminated by hypothalamic lesions. Proc Natl Acad Sci USA 69: 1583-1586, 1972.

2. Bartness TJ, Song CK and Demas GE: SCN efferents to peripheral tissues: implications for biological rhythms. J Biol Rhythms 16: 196-204, 2001.

3. Reppert SM and Weaver DR: Coordination of circadian timing in mammals. Nature 418: 935-941, 2002.

4. Herzog ED: Neurons and networks in daily rhythms. Nat Rev Neurosci 8: 790-802, 2007.

5. Liu AC, Welsh DK, Ko CH, et al: Intercellular coupling confers robustness against mutations in the SCN circadian clock network. Cell 129: 605-616, 2007.

6. Kuhlman SJ and McMahon DG: Encoding the ins and outs of circadian pacemaking. J Biol Rhythms 21: 470-481, 2006.

7. Lee C, Etchegaray JP, Cagampang FR, Loudon AS and Reppert SM: Posttranslational mechanisms regulate the mammalian circadian clock. Cell 107: 855-867, 2001.

8. Ko CH and Takahashi JS: Molecular components of the mammalian circadian clock. Hum Mol Genet 15: R271-R277, 2006.

9. Schibler U: The daily timing of gene expression and physiology in mammals. Dialogues Clin Neurosci 9: 257-272, 2007.

10. Oishi K, Miyazaki K, Kadota K, et al: Genome-wide expression analysis of mouse liver reveals CLOCK-regulated circadian output genes. J Biol Chem 278: 41519-41527, 2003.

11. Lowrey PL and Takahashi JS: Mammalian circadian biology. elucidating genome-wide levels of temporal organization. Annu Rev Genomics Hum Genet 5: 407-441, 2004.
12. Schernhammer ES, Laden F, Speizer FE, et al: Rotating night shifts and risk of breast cancer in women participating in the nurses' health study. J Natl Cancer Inst 93: 1563-1568, 2001.

13. Schernhammer ES, Laden F, Speizer FE, et al: Night-shift work and risk of colorectal cancer in the nurses' health study. J Natl Cancer Inst 95: 825-828, 2003.

14. Viswanathan AN, Hankinson SE and Schernhammer ES: Night shift work and the risk of endometrial cancer. Cancer Res 67: 10618-10622, 2007.

15. Sack RL, Auckley D, Auger RR, et al: Circadian rhythm sleep disorders: part I, basic principles, shift work and jet lag disorders. An American Academy of Sleep Medicine review. Sleep 30: 1460-1483, 2007.

16. Filipski E, King VM, Li X, et al: Host circadian clock as a control point in tumor progression. J Natl Cancer Inst 94: 690-697, 2002.

17. Koyanagi S, Kuramoto Y, Nakagawa H, et al: A molecular mechanism regulating circadian expression of vascular endothelial growth factor in tumor cells. Cancer Res 63: 7277-7283, 2003.

18. Cao Q, Gery S, Dashti A, Zhou Y, Gu J and Koeffler HP: A role for the clock gene perl in prostate cancer. Cancer Res 69: 7619-7625, 2009

19. Fu L, Pelicano H, Liu J, Huang P and Lee C: The circadian gene Period2 plays an important role in tumor suppression and DNA damage response in vivo. Cell 111: 41-50, 2002.

20. Hua $\mathrm{H}$, Wang $\mathrm{Y}$, Wan $\mathrm{C}$, et al: Circadian gene mPer2 overexpression induces cancer cell apoptosis. Cancer Sci 97: 589-596, 2006.

21. Oda A, Katayose Y, Yabuuchi S, et al: Clock gene mouse period2 overexpression inhibits growth of human pancreatic cancer cells and has synergistic effect with cisplatin. Anticancer Res 29: 1201-1209, 2009.

22. Chen ST, Choo KB, Hou MF, Yeh KT, Kuo SJ and Chang JG: Deregulated expression of the PER1, PER2 and PER3 genes in breast cancers. Carcinogenesis 26: 1241-1246, 2005.

23. Winter SL, Bosnoyan-Collins L, Pinnaduwage D and Andrulis IL: Expression of the circadian clock genes Per1 and Per2 in sporadic and familial breast tumors. Neoplasia 9: 797-800, 2007.

24. Yeh KT, Yang MY, Liu TC, et al: Abnormal expression of period 1 (PER1) in endometrial carcinoma. J Pathol 206: 111-120, 2005.

25. Yang WS and Stockwell BR: Inhibition of casein kinase 1-epsilon induces cancer-cell-selective, PERIOD2-dependent growth arrest. Genome Biol 9: R92, 2008.

26. Roy PG and Thompson AM: Cyclin D1 and breast cancer. Breast 15: 718-727, 2008.

27. Koyanagi S, Kuramoto Y, Nakagawa H, et al: A molecular mechanism regulating circadian expression of vascular endothelial growth factor in tumor cells. Cancer Res 63: 7277-7283, 2003.

28. Taniguchi H, Fernández AF, Setién F, et al: Epigenetic inactivation of the circadian clock gene BMAL1 in hematologic malignancies. Cancer Res 69: 8447-8454, 2009.

29. Kuo SJ, Chen ST, Yeh KT, et al: Disturbance of circadian gene expression in breast cancer. Virchows Arch 454: 467-474, 2009.

30. Chen-Goodspeed M and Lee CC: Tumor suppression and circadian function. J Biol Rhythms 22: 291-298, 2007.

31. Sjöblom T, Jones S, Wood LD, et al: The consensus coding sequences of human breast and colorectal cancers. Science 314: 268-274, 2006.

32. Hua H, Wang Y, Wan C, et al: Inhibition of tumorigenesis by intratumoral delivery of the circadian gene mPer2 in C57BL/6 mice. Cancer Gene Ther 14: 815-818, 2007.

33. Gery S, Virk RK, Chumakov K, Yu A and Koeffler HP: The clock gene Per2 links the circadian system to the estrogen receptor. Oncogene 26: 7916-7920, 2007. 